\title{
Development of ATHENA mirror modules
}

Collon, Maximilien J.; Vacanti, Giuseppe; Barrĩ̃"re, Nicolas M.; Landgraf, Boris; GÃ $1 / 4 n$ ther, Ramses; Vervest, Mark; Van Der Hoeven, Roy; Dekker, Danielle; Chatbi, Abdel; Girou, David Alain

Total number of authors:

36

Published in:

Optics for EUV, X-Ray, and Gamma-Ray Astronomy VIII;

Link to article, DOI:

$10.1117 / 12.2273704$

Publication date:

2017

Document Version

Publisher's PDF, also known as Version of record

Link back to DTU Orbit

Citation (APA):

Collon, M. J., Vacanti, G., BarriÃ̈re, N. M., Landgraf, B., GÃ¹/4nther, R., Vervest, M., Van Der Hoeven, R., Dekker, D., Chatbi, A., Girou, D. A., Sforzini, J., Beijersbergen, M. W., Bavdaz, M., Wille, E., Fransen, S., Shortt, B., Haneveld, J., Koelewijn, A., Booysen, K., ... Pareschi, G. (2017). Development of ATHENA mirror modules. In S. L. O'Dell, \& G. Pareschi (Eds.), Optics for EUV, X-Ray, and Gamma-Ray Astronomy VIII; (Vol. 10399). SPIE - International Society for Optical Engineering. Proceedings of SPIE - The International Society for Optical Engineering https://doi.org/10.1117/12.2273704

\section{General rights}

Copyright and moral rights for the publications made accessible in the public portal are retained by the authors and/or other copyright owners and it is a condition of accessing publications that users recognise and abide by the legal requirements associated with these rights.

- Users may download and print one copy of any publication from the public portal for the purpose of private study or research.

- You may not further distribute the material or use it for any profit-making activity or commercial gain

- You may freely distribute the URL identifying the publication in the public portal 


\section{Development of ATHENA mirror modules}

\section{Maximilien J. Collon, Giuseppe Vacanti, Nicolas M. Barrière, Boris Landgraf, Ramses Günther, et al.}

Maximilien J. Collon, Giuseppe Vacanti, Nicolas M. Barrière, Boris Landgraf, Ramses Günther, Mark Vervest, Roy van der Hoeven, Danielle Dekker, Abdel Chatbi, David Girou, Jessica Sforzini, Marco W. Beijersbergen, Marcos Bavdaz, Eric Wille, Sebastiaan Fransen, Brian Shortt, Jeroen Haneveld, Arenda Koelewijn, Karin Booysen, Maurice Wijnperle, Coen van Baren, Alexander Eigenraam, Peter Müller, Michael Krumrey, Vadim Burwitz, Giovanni Pareschi, Sonny Massahi, Finn E. Christensen, Desirée Della Monica Ferreira, Giuseppe Valsecchi, Paul Oliver, lan Checquer, Kevin Ball, Karl-Heinz Zuknik, "Development of ATHENA mirror modules," Proc. SPIE 10399, Optics for EUV, X-Ray, and Gamma-Ray Astronomy VIII, 103990C (29 August 2017); doi: 10.1117/12.2273704

Event: SPIE Optical Engineering + Applications, 2017, San Diego, California, United States 


\title{
Development of Athena mirror modules
}

\author{
Maximilien J. Collon ${ }^{*}$, Giuseppe Vacanti ${ }^{1}$, Nicolas M. Barrière ${ }^{1}$, Boris Landgraf ${ }^{1}$, Ramses \\ Günther ${ }^{1}$, Mark Vervest ${ }^{1}$, Roy van der Hoeven ${ }^{1}$, Danielle Dekker ${ }^{1}$, Abdel Chatbi ${ }^{1}$, David Girou ${ }^{1}$, \\ Jessica Sforzini ${ }^{1}$, Marco W. Beijersbergen ${ }^{1}$, Marcos Bavdaz ${ }^{2}$, Eric Wille ${ }^{2}$, Sebastiaan Fransen ${ }^{2}$, \\ Brian Shortt ${ }^{2}$, Jeroen Haneveld ${ }^{3}$, Arenda Koelewijn ${ }^{3}$, Karin Booysen ${ }^{3}$, Maurice Wijnperle ${ }^{3}$, Coen \\ van Baren ${ }^{4}$, Alexander Eigenraam ${ }^{4}$, Peter Müller ${ }^{5}$, Michael Krumrey ${ }^{5}$, Vadim Burwitz ${ }^{6}$, Giovanni \\ Pareschi $^{7}$, Sonny Massahi ${ }^{8}$, Finn E. Christensen ${ }^{8}$, Desirée Della Monica Ferreira ${ }^{8}$, Giuseppe \\ Valsecchi $^{9}$, Paul Oliver ${ }^{10}$, Ian Chequer ${ }^{10}$, Kevin Ball ${ }^{10}$, Karl-Heinz Zuknik ${ }^{11}$ \\ ${ }^{1}$ cosine, Oosteinde 36, $2361 \mathrm{HE}$ Warmond, The Netherlands \\ 2 European Space Agency, ESTEC, Keplerlaan 1, PO Box 299, 2200 AG Noordwijk, The \\ Netherlands \\ ${ }^{3}$ Micronit Microfluidics B.V., Colosseum 15, 7521 PV Enschede, The Netherlands \\ ${ }^{4}$ SRON, Sorbonnelaan 2, 3584 CA Utrecht, The Netherlands \\ ${ }^{5}$ Physikalisch-Technische Bundesanstalt (PTB), Abbestr. 2-12, 10587 Berlin, Germany \\ ${ }^{6}$ MPI f. extraterrestrische Physik, Giessenbachstrasse 1, 85748 Garching, Germany \\ ${ }^{7}$ INAF Osservatorio Astronomico di Brera, Via E. Bianchi 46 I- 23807, Merate (Lc), Italy \\ ${ }^{8}$ DTU Space, Technical University of Denmark, Building 327, DK - 2800 Kgs. Lyngby, Denmark \\ ${ }^{9}$ Media Lario S.r.1., Località Pascolo, 23842 Bosisio Parini(LC), Italy \\ ${ }^{10}$ Teledyne e2v (UK) Ltd., 106 Waterhouse Lane, Chelmsford, Essex CM1 2QU, England \\ ${ }^{11}$ OHB System AG, Manfred-Fuchs-Straße 1, 82234 Weßling, Germany
}

\begin{abstract}
Silicon Pore Optics (SPO), developed at cosine with the European Space Agency (ESA) and several academic and industrial partners, provides lightweight, yet stiff, high-resolution x-ray optics. This technology enables ATHENA to reach an unprecedentedly large effective area in the $0.2-12 \mathrm{keV}$ band with an angular resolution better than $5 "$. After developing the technology for $50 \mathrm{~m}$ and $20 \mathrm{~m}$ focal length, this year has witnessed the first $12 \mathrm{~m}$ focal length mirror modules being produced. The technology development is also gaining momentum with three different radii under study: mirror modules for the inner radii $\left(R_{\min }=250 \mathrm{~mm}\right)$, outer radii $\left(R_{\max }=1500 \mathrm{~mm}\right)$ and middle radii $\left(R_{\text {mid }}=737 \mathrm{~mm}\right)$ are being developed in parallel.
\end{abstract}

Keywords: X-ray optics, X-ray astronomy, silicon, wafer, stack, pore optics, X-ray telescopes, ATHENA, SPO

\section{INTRODUCTION}

The development of SPO [1-25] has gained significant momentum with the adoption of ATHENA [26] as second L (large) mission of the ESA Cosmic Vision 2015-2025 program. ATHENA, currently under study in phase A [27], will be the largest X-ray observatory flown to date, with a $\sim 3 \mathrm{~m}$ diameter X-ray lens [28] and two detectors, one to perform spatially-resolved high resolution spectroscopy (X-IFU) at cryogenic temperatures and a Wide Field Imager (WFI) to perform imaging spectroscopy.

The launch date of ATHENA is set to 2028, which requires a formal mission adoption in 2020. The adoption requires amongst other items the optics to reach a technology readiness level (TRL) of 6, which shall be demonstrated by building and testing a segment of the optic, populated with three types of SPO mirror modules. The test shall demonstrate that ATHENA can reach the required angular resolution of 5", and survive the harsh conditions of launch and operation. For this reason ESA had started several activities [30] that cover amongst others the development of SPO modules for three types of radii, as depicted in Figure 1.

*m.collon@cosine.nl; phone 00317152849 62; cosine.nl

Optics for EUV, X-Ray, and Gamma-Ray Astronomy VIII, edited by Stephen L. O'Dell, Giovanni Pareschi, Proc. of SPIE Vol. 10399, 103990C · C 2017 SPIE · CCC code: 0277-786X/17/\$18 · doi: 10.1117/12.2273704 
SPO development was focused in the last years on producing optic for a focal length of $20 \mathrm{~m}$, a requirement stemming from earlier mission proposals. The year 2016 marked then the transition to the ATHENA focal length of $12 \mathrm{~m}$, including the development of all the necessary parts and equipment to develop and produce mirror modules at three representative radii, as further described in this paper.

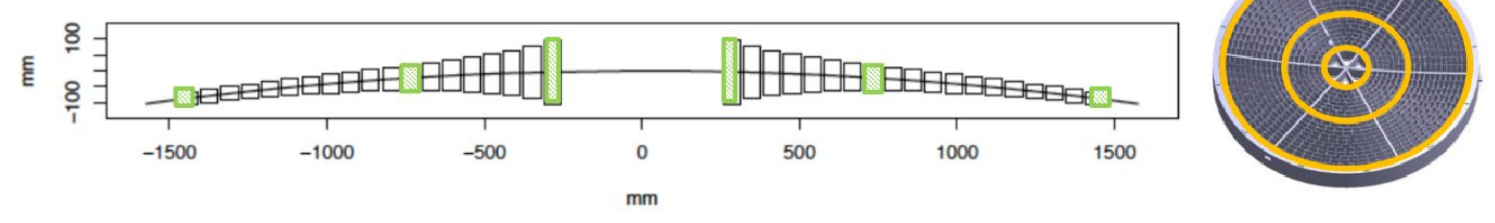

Figure 1. Cross section through the ATHENA optic (left). ATHENA optical bench as seen from the top (right). The radii for which SPO is being development are marked in green (left) and yellow (right). The innermost radius is $250 \mathrm{~mm}$, the outermost $1500 \mathrm{~mm}$ and as middle radius we chose $737 \mathrm{~mm}$.

\section{PLATE DEVELOPMENT}

The production capacity for making SPO plates has been increased by an order of magnitude to several thousand plates per year, to accommodate the demands of the different development activities. This required a review of all of the involved production processes, from wafer sourcing, over plate dicing, ribbing, coating to plate transport and inspection. The overall plate production process has already been described in [7].

As a result we have developed three types of wedged plates (see Figure 2), one per development radius, each of which demonstrates different plate production techniques:

1. Inner radius plates with a length of $110 \mathrm{~mm}$ and an azimuthal width of $49 \mathrm{~mm}$. Those feature a rib spacing of $2.3 \mathrm{~mm}$ to demonstrate the possibility to increase the field of view. To reduce springback effects the plates have a membrane thickness of only $140 \mu \mathrm{m}$.

2. Middle radius plates with a length of $40 \mathrm{~mm}$ and a width of $66 \mathrm{~mm}$. These plates are created by dicing already ribbed $66 \times 66 \mathrm{~mm}^{2}$ plates into a shorter length, to remove wedging artefacts.

3. Outer radius plates with a length of $21 \mathrm{~mm}$ and a width of $102 \mathrm{~mm}$, which are created by dicing larger wedged plates into shorter segments. This is done to test increasing the production efficiency.

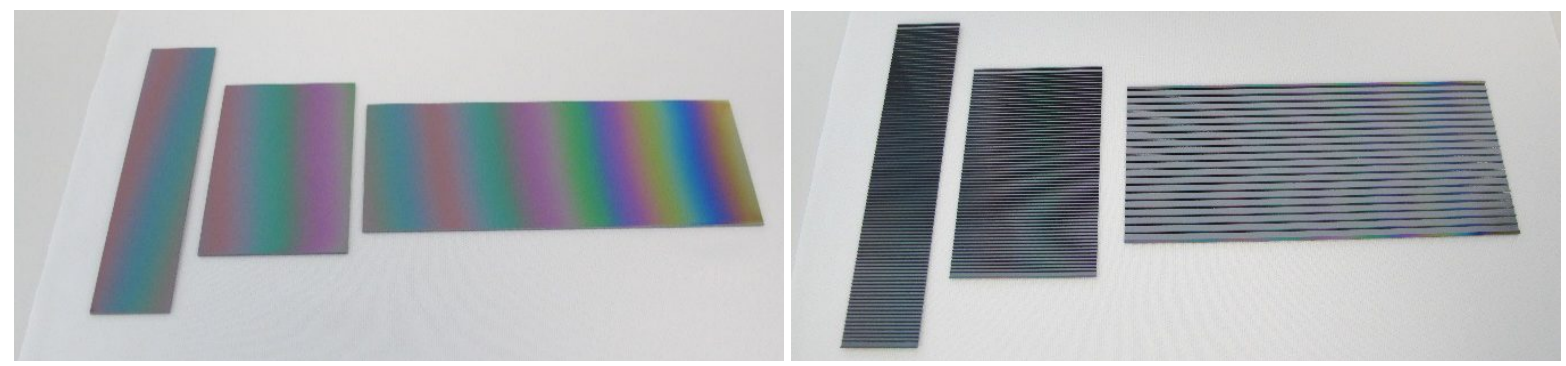

Figure 2. Three types of plates developed for the $f=12 \mathrm{~m} \mathrm{SPO} \mathrm{development.} \mathrm{The} \mathrm{left} \mathrm{picture} \mathrm{shows} \mathrm{the} \mathrm{reflective} \mathrm{side,} \mathrm{the}$ right picture the ribbed side. In each picture the outer radius plate is left, middle radius plate is in the centre and the inner radius plate is on the right.

We have also upgraded the wet benches, dicing machines and lithography equipment to be able to handle large volume of plates. A second plate supplier is in the process of commissioning its plate production equipment and will start to deliver first wedged plates as of November 2017.

The larger number of plates to be processed also required an update of incoming inspection equipment, to automatically process the plate production measurement data (e.g. wedging profiles), measure the cleanliness of the plates, check their 
dimensions and compare the results to newly defined acceptance/rejection criteria. Those criteria have been synchronized with the plate suppliers and ongoing work concerns the development of a total thickness variation measurement equipment for wedged plates, as so far we have been limited to measuring the thickness variation of the wedge itself.

To prepare plates for coating, a lithographic mask has to be applied. We have improved the deposition process in order to minimize any residual contamination left after lifting off the mask after coating. The coating process itself is based on magnetron sputtering of materials such as $\operatorname{Ir}$ and $\mathrm{B}_{4} \mathrm{C}$, where the development and optimization of the coating recipe is being performed by the Danish Technical University (DTU), as discussed elsewhere in this conference [29]. Together we have focused on selecting a coating machine large enough and suitable to coat up to 100.000 plates per year, in line with the requirements of the ATHENA mission. After a detailed trade-off a drum sputter coating system from a German supplier has been selected and ordered (Figure 3), which will be installed at cosine early 2018. It can coat up to 150 plates in one run, enough to make 4 stacks for a mirror module.

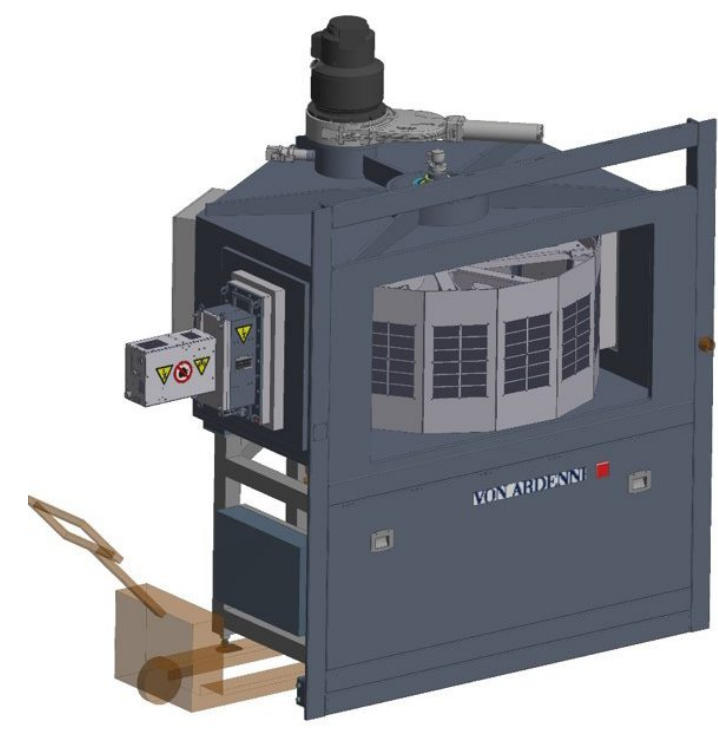

Figure 3. Schematics of the drum sputter coating system with the loading door removed, showing the carrousel that moves carriers with SPO plates past three magnetrons. The chamber is about $2 \mathrm{~m}$ high, with a diameter of about $1.8 \mathrm{~m}$ and it can coat up to 100.000 plates per year.

\section{STACKING PROCESS DEVELOPMENT}

The stacking process has been described in detail elsewhere [21] and can be roughly summarized as follows: A set of plates is cleaned in a wet bench to remove particulate contamination and to activate them for bonding.

Then the cleaned plates are loaded into a dedicated stacking robot, which carries out the following sequential tasks:

1. Inspection of the cleanliness of each plate

2. Plate deposition

a. Only first plate: deposition of the first plate on a concave super-polished mandrel to provide the correct figure

b. All other plates: Pre-bending of the plate into a convex shape using a so-called die, then bonding onto previous plate

3. Figure measurement of each bonded plate using a fringe reflection technique

Steps 1-3 are repeated 35 times, until the stack is completed and it can be removed from the mandrel. In the following sub-chapters we describe the various development that were carried out recently. 


\subsection{Inner radius developments}

The major difficulty to overcome was developing a pre-forming die that can adjust for the $118 \mu \mathrm{m}$ difference in sag due to the curvature change when stacking 35 plates starting from a radius of of $277 \mathrm{~mm}$ down to a radius of $250 \mathrm{~mm}$. For this we have developed a novel die concept using so-called changeable heads, that can better pre-shape the plates into a convex conical form to facilitate the bonding step.

We also designed and procured a set of inner radii silicon mandrels from Carl-Zeiss, having the required conical shape to form a primary and secondary stack in approximation of a Wolter-I optics [30]. The secondary mandrel also has a meridional curvature in order to meet the angular resolution requirement at a focal length of $12 \mathrm{~m}$.

All other parts required for an inner radius stacking robot were procured and installed and we commissioned the first inner radius stacking robot in September 2016. The stacking robot was then used to perform trial stacking in November 2016 and we achieved to produce a first ever conical stack of 35 plates (see Figure 4) with an innermost radius of curvature of $250 \mathrm{~mm}$. While this stack demonstrated that we could successfully bond plates together at this small radius of curvature, it also highlighted a number of smaller issues that still need to be tackled, such as the cleanliness of the new mandrels, the speed at which we can exchange the die heads and the stacking of coated plates at this radius.

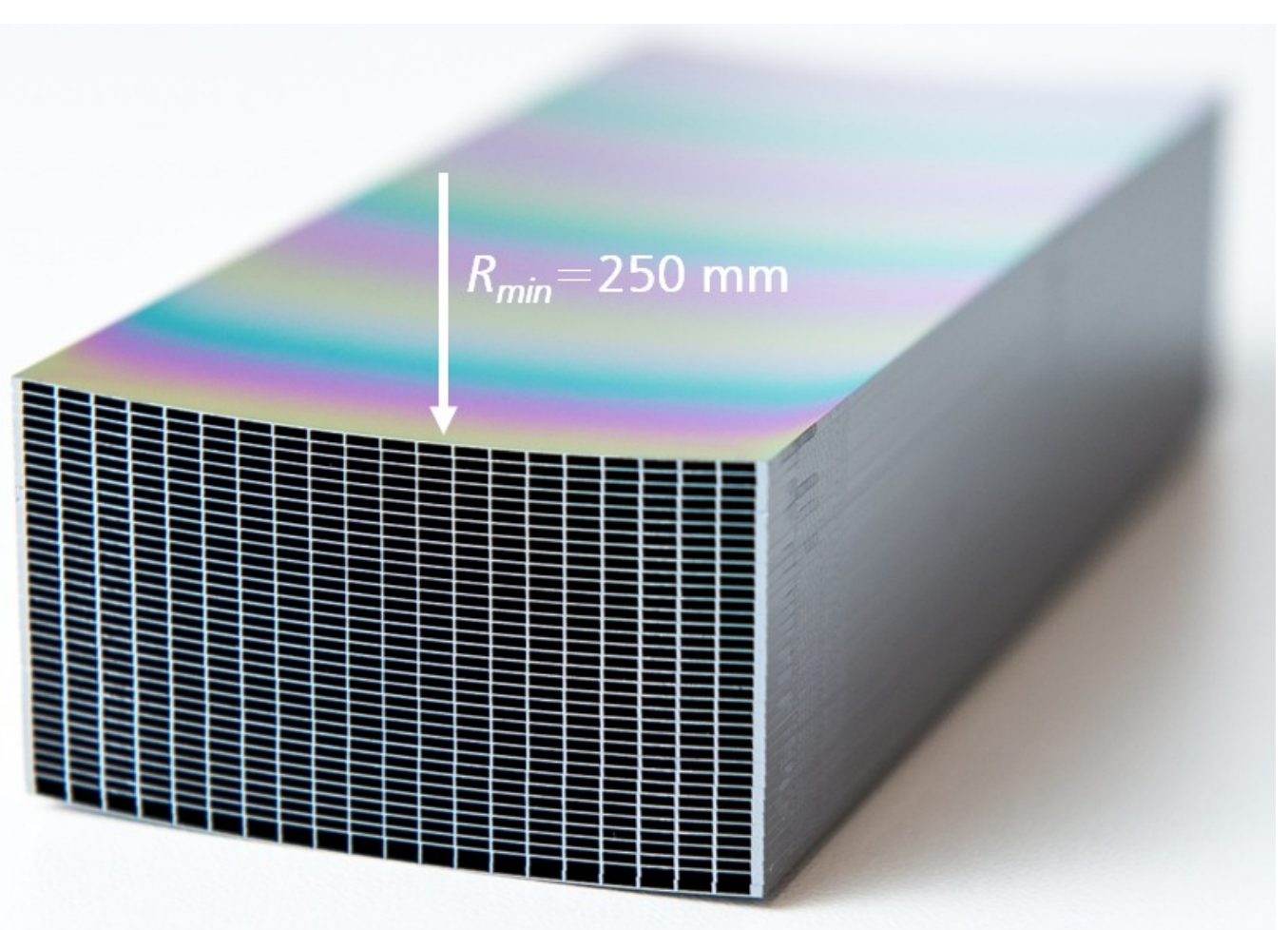

Figure 4. First ever inner radius stack of 35 plates, with an innermost radius of $R_{\min }=250 \mathrm{~mm}$.

We are now proceeding to manufacture several stacks that will be combined into a mirror module to be measured in $\mathrm{x}$ rays in double reflection. For this step we have already developed the required set of mounting brackets and manufactured an assembly jig (see Figure 5), which allows gluing two pairs of primary-secondary stacks into two invar brackets, then forming a SPO mirror module. The process of gluing stacks into brackets has already been demonstrated several times at other focal lengths for middle radius stacks and is further discussed elsewhere in these proceedings [37]. 


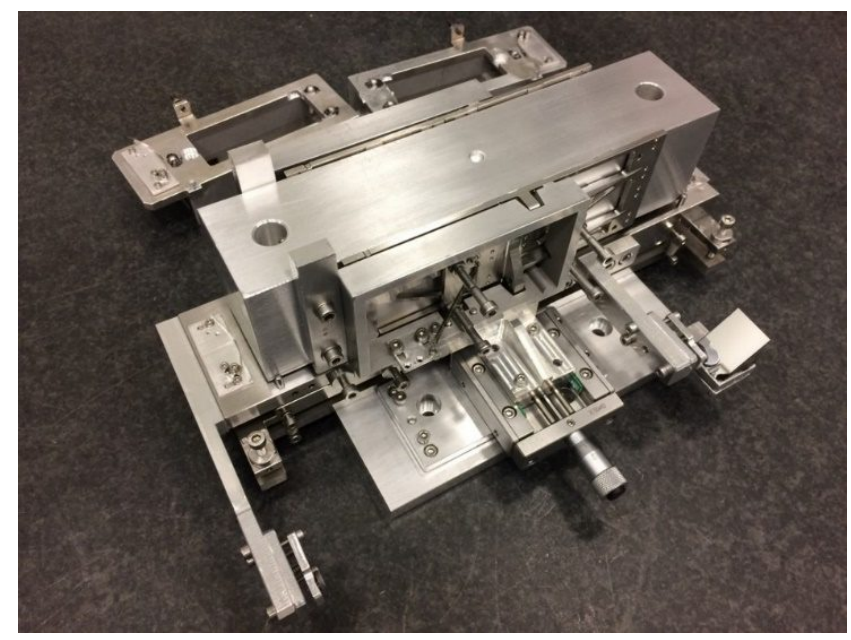

Figure 5. Inner radius mirror module assembly jig. Note that the large aluminum block in the centre between the two Invar brackets is only an alignment device for the calibration of the jig.

\subsection{Middle radius developments}

The $f=20 \mathrm{~m}$ middle radius stacking equipment has been the only stacking process development work-horse for several years. In July 2016 a pair of 20 plate stacks was measured in double reflection at the PANTER [35] test facility of the Max Plank Institut für extraterrestrische Physik (MPE). The point spread function (PSF) had a half-energy width (HEW) of $13.9 "$ at $1.49 \mathrm{keV}$, with the central $60 \%$ of the width of the stacks having a HEW of 8 " [21]. With these very promising results it was decided to transition to a focal length of $12 \mathrm{~m}$, which started in September 2016 with the development of shorter wedged plates with a length of $40 \mathrm{~mm}$. We decided to keep the width at $66 \mathrm{~mm}$, in order to minimize changes to existing equipment. Nevertheless, the shorter length required the procurement of new mandrels from Carl-Zeiss and also of new dies. The $f=20 \mathrm{~m}$ stacking robot still used dies with vacuum suction to pre-form the plate. For the $12 \mathrm{~m}$ focal length we developed novel dies with electrostatic plate attachment. Those have a continuous surface, which improves the figure of a stacked plate closed to its edges. We also invested in the further industrialisation of the production equipment in order to increase the stacking speed from 45 minutes to less than 20 minutes per plate, which allows producing a stack within a single day.
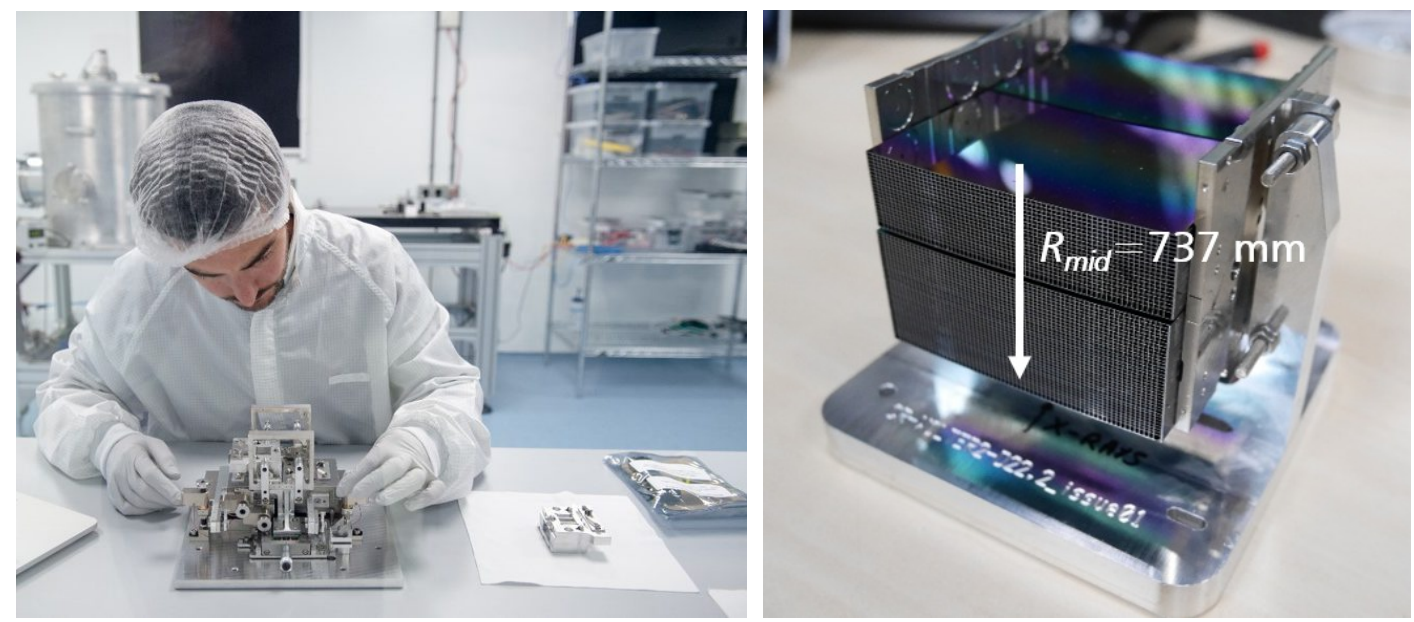

Figure 6. Left: Testing of the middle radius mirror module integration jig. Right: First ever $f=12 \mathrm{~m}$ middle radius mirror module. 
In October 2016 two first pairs of 20 and 35 plate test stacks were fabricated to ensure the functionality of all new components. The stacking metrology indicated that these stacks would not yet yield a small PSF, as is to be expected when commissioning new equipment and having to adjust the process parameters first. The transversal width of the PSF however, important for mission proposals such as ARCUS [34], was measured at the NASA Marshall Straylight Test Facility (SLTF) in Huntsville to be 1.42" Full Width Half Maximum (FWHM) [34]. In combination with a Critical Angle Transmission (CAT) grating [32] a resolution of $>2500$ was achieved. To also test the new mirror module brackets and integration tools, it was decided to integrate the stacks at the XPBF 1.0 facility [23] of the Physikalisch-Technische Bundesanstalt (PTB) at the BESSY synchrotron radiation facility into a mirror module (see Figure 6).

With these very encouraging results we are now proceeding to tune the process parameters of the new stacking robot and to adjust the design of the electrostatic die in order to manufacture mirror modules that shall approach the goal of a 4.3" HEW. To this end, a larger number of tests stacks will be produced in the coming months and will be assembled into mirror modules, serving as test objects for other ESA activities [38, 39].

\subsection{Outer radius developments}

In June 2017 we have finished the assembly of the first stacking robot to make stacks for a focal length of $12 \mathrm{~m}$ with an outer radius of curvature of $1500 \mathrm{~mm}$, bringing the total of active stacking robots to three. Similar to the inner and middle radius activities we had to develop new mandrels, dies, brackets and assembly jigs. Several smaller test stacks have been made (Figure 7) and the process of tuning the stacking parameters has started. We expect to make the first 35 plate stacks in the second half of 2017 and to produce the first mirror module in Q2/2018.
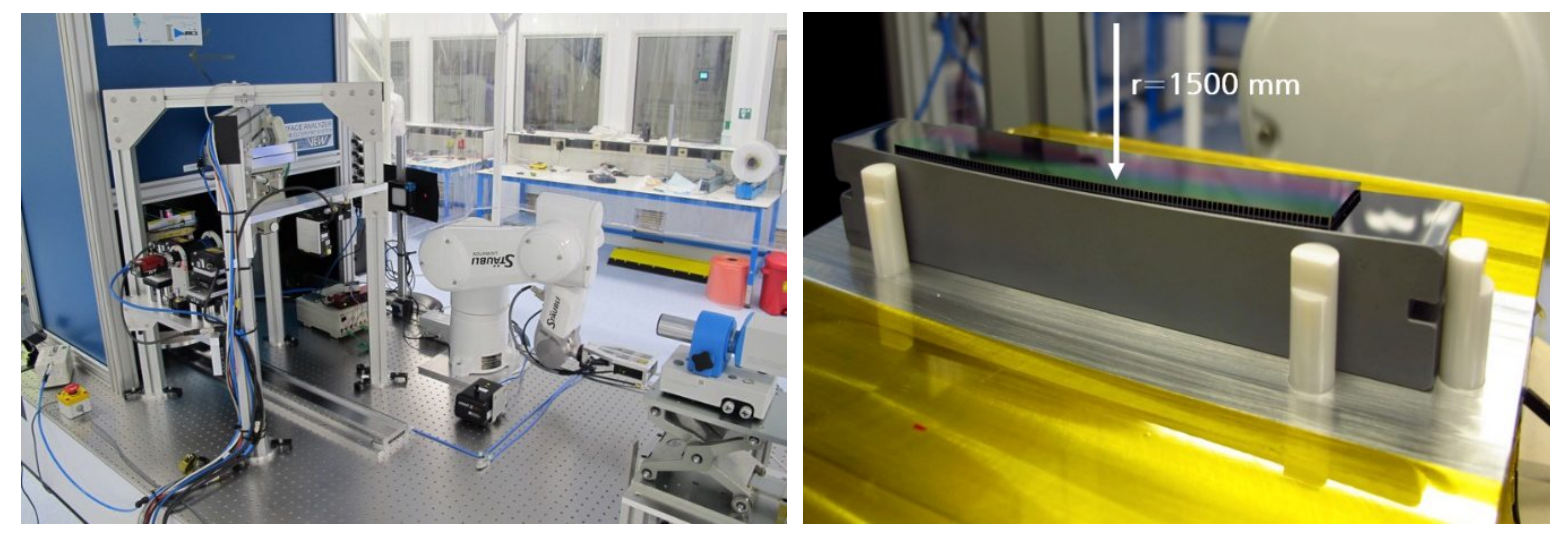

Figure 7. The outer radius $\left(R_{\text {out }}=1500 \mathrm{~mm}, f=12 \mathrm{~m}\right)$ stacking robot is operational (left). The right picture shows the very first test stack of 2 plates, still on the mandrel.

\section{CONCLUSIONS}

The Silicon Pore Optics development is progressing and addressing all critical areas (resolution, production rates, environmental qualification) in parallel, according to the technology development plan of ESA. The transition from $20 \mathrm{~m}$ to $12 \mathrm{~m}$ focal length has been completed. Stacking robots for three different representative radii of ATHENA have been installed and have produced first stacks for inner, middle and outer radii, in a newly commissioned stacking facility. The stacking process development is ongoing for all three representative radii, together with a number of other activities that address the mirror modules integration in the mirror structure [38, 39], ruggedisation [33], simulation [25] and the coating [36] of the optics.

\section{REFERENCES}

[1] Beijersbergen, M. et al., "Silicon pore optics: novel lightweight high-resolution X-ray optics developed for XEUS", Proc. SPIE 5488, 868-874 (2004).

[2] Bavdaz, M. et al., "Progress at ESA on high-energy optics technologies", Proc. SPIE 5168, 136-147 (2004). 
[3] Kraft, S. et al., "Development of modular high-performance pore optics for the XEUS x-ray telescope", Proc. SPIE 5900, 297-308 (2005).

[4] Günther, R. et al., "Production of silicon pore optics", Proc. SPIE 6266, 626619 (2006).

[5] Collon, M. J. et al., "Performance characterization of silicon pore optics", Proc. SPIE 6266, 62661T (2006).

[6] Freyberg, M. et al., "Potential of the PANTER x-ray test facility for calibration of instrumentation for XEUS", Proc. SPIE 6266, 62663H (2006).

[7] Olde Riekerink, M. B. et al. "Production of silicon mirror plates", Proc. SPIE 7437, 74370U (2009)

[8] Wallace, K. et al, "Silicon pore optics development", Proc. SPIE 7437, 7437 (2009).

[9] Collon, M. J., et al., "Stacking of silicon pore optics for IXO", Proc. SPIE, 7437 (2009).

[10] Jensen, C. P. et al., "Coating of silicon pore optics", Proc. SPIE 7437, 7437 (2009).

[11] Vacanti, G, et al., "Silicon pore optics for astrophysical missions", Proc. SPIE 7732, 773240 (2010).

[12] Ackerman, M, et al., "Compatibility of silicon pore optics with launchers and operation conditions", Proc. SPIE 8147, 81470D (2011).

[13] Bavdaz, M. et al., "ESA optics technology preparation for IXO", Proc. SPIE 7732, 77321E (2010).

[14] Wille, E., et al., "Mass Production of Silicon Pore Optics for IXO and ATHENA", Proc. SPIE 8147, 81470D (2011).

[15] Wille, M. et al., "Qualification of silicon pore optics", Proc. SPIE 9144, 91442H (2014).

[16] Bavdaz, M. et al, "The ATHENA Optics", Proc. of SPIE Vol. 9603, 96030J (2015)

[17] Collon, M., et al, "Silicon Pore Optics development for ATHENA", Proc. SPIE 9603 (2015).

[18] Ayre, M., et al, "ATHENA: system design and implementation for a next generation x-ray telescope", Proc. SPIE 9601 (2015).

[19] Vacanti, G., et al, "New ray-tracing capabilities for the development of silicon pore optics", Proc. SPIE 9603 (2015).

[20] Wille, E.; Bavdaz, M. \& Collon, M., "Mass production of silicon pore optics for ATHENA", Proc. SPIE 9905 (2016).

[21] Collon, M., et al, "Silicon pore optics for the ATHENA telescope", Proc. SPIE 9905 (2016).

[22] Bavdaz, M., et al, "The ATHENA optics development", Proc. SPIE 9905 (2016).

[23] Krumrey, M., et al, "X-ray pencil beam facility for optics characterization", Proc. SPIE 7732, 773240 (2010).

[24] Krumrey, M., et al, "New X-ray parallel beam facility XPBF 2.0 for the characterization of silicon pore optics", Proc. SPIE 9905 (2016).

[25] Spiga, D., et al, "Simulation and modeling of silicon pore optics for the ATHENA x-ray telescope", Proc. SPIE 9905 (2016).

[26] K. Nandra, "Athena: Exploring the Hot and Energetic Universe", Proc. American Astronomical Society HEAD meeting (\#14), (2014).

[27] Ayre, M., et al, "ATHENA: system studies and optics accommodation", Proc. SPIE 9905, 990526 (2016)

[28] R. Willingale, G. Pareschi, F. Christensen, J-W. den Herder, "The Optical Design of the Athena+ Mirror", An ATHENA+ supporting paper, $<$ http://www.the-athena-x-ray-observatory.eu/

[29] Della Monica Ferreira, D., et al, "Design, development, and performance of X-ray mirror coatings for the ATHENA mission", Proc. SPIE 10399 (2017).

[30] Wolter, H., "Spiegelsysteme streifenden Einfalls als abbildende Optiken für Röntgenstrahlen", Annalen der Physik 445, 94-114 (1952).

[31] Bavdaz, M., et al, “The ATHENA Telescope and Optics Status”, Proc. SPIE 10399 (2017).

[32] Heilmann, R. K., et al, "Critical-angle transmission grating technology development for high resolving power soft x-ray spectrometers on Arcus and Lynx", Proc. SPIE 10399 (2017).

[33] Landgraf, B., et al, "Environmental testing of the Athena mirror modules", Proc. SPIE 10399 (2017).

[34] Smith, R. K., el al, “Arcus: The X-ray Grating Spectrometer Explorer”, Proc. SPIE 10397 (2017).

[35] Burwitz, V., et al, "Testing and calibrating the Athena optics at PANTER", Proc. SPIE 10399 (2017).

[36] Massahi, S., et al, "Industrialization of the mirror plate coatings for the Athena mission", Proc. SPIE 10399 (2017).

[37] Barrière, N. M., et al, "Silicon pore optics mirror module assembly process", Proc. SPIE 10399 (2017).

[38] Valsecchi, G. et al, "Optical integration of the SPO modules in the ATHENA telescope", Proc SPIE 10399 (2017).

[39] Vernani, D., et al, "Integration of the Athena mirror modules: development of indirect and X-ray direct AIT methods", Proc SPIE 10399 (2017). 